Probeflüssigkeit und das Vermeiden der Salpetersäure zur Oxydation des Eisens nöthig. (Berg-u. Hittenm. Ztg. 1854. p. 280. - Polyt. Centrbl. 1854. No. 19. p. 1210) Mr.

\title{
Meteoreisen in Grönland.
}

Dr. Rink fand in einer Eskimohiitte zu Niakornak, zwischen Rittenbeck und Jacobshavn einen Eisenklumpen 21 Pfd. schwer von 7,0-7,07 spec. Gewicht. Die chemische Untersuchung ergab ungewöhnlich viel Kohlenstoff und ausserdem noch Spuren von Metallen aus der Thonerden-, Zirkonerden- und Yttererden-Reihe. Die Widmannstättenschen Figuren zeigen sich sehr deutlich, nur kleiner, als gewöhnlich. Die schwerer, als die Hauptmasse, auföslichen Körner bestehen nur aus Eisen und Kohle, und zwar fanden sich in denselben $7,23 \mathrm{ja}$ in andern Körnern 11,06 Proc. Kohle.

Der Verf. bezeichnet das zu Niakornak gefundene eigenthümliche Meteoreisen seines Gehaltes an Kohle, seiner Härte und Sprödigkeit wegen als Meteorgusseisen zum Unterschied von dem, welches Parry aus dem nördlich von den dänischen Colonien gelegenen Grönland nach England gebracht hatte. Dies Metcoreisen ist so weich, dass die Eskimos Messer daraus gefertigt hätten, deshalb nennt er es Meteorschmiedeeisen. - Noch eine dritte Meteoreisenmasse, aus dem südlichen Grönland stammend, besitzt der Etats-Ratl Forchhammer, welche nach den vorläufig angestellten Untersucliungen zu dem Meteorschmiedeeisen gehören dürfte. (Pogg. Annal. 1854. No.9. p. $1 \tilde{5} \tilde{5}-158$.)

$M r$.

\section{Molybdänsaures Ammoniak.}

H. Krause in Freyberg empfiehlt zur Darstellung des molybdänsauren Ammoniaks den Molybdänglanz, welchen man in der bergacademischen Mineral-Niederlage in Freiberg ziemlich rein, das Pfund für 22/3 Thlr., bekommt. Man hat hier nur nöthig, den Molybdänglanz, fein gepulvert, zu glïhen, mit Ammoniak auszuziehen und die Lösung zur Krystallisation zu verdunsten. Der Rückstand wird von Neuem vorsichtig geglüht und wieder mit Ammoniak behandelt, welche Operation man wohl sechsmal mit Vortheil wiederholen kann. (Zeitschr. fiur Pharm. 1854. No. 11. p. 162.) Mr. 